\title{
ĐÁNH GIÁ KẾT QUẢ ĐIỀU TRI ĐỨT BÁN PHẦN GÂN TRÊN GAI BẰNG LIẸU PHÁP HUYẾT TƯƠNG GIÀU TIỂU CẦU DƯớI HƯớNG DẪN CỦA SIÊU ÂM
}

\author{
Nguyễn Thị Phương1,2, Nguyễn Thị Ngọc Lan ${ }^{1}$, Phạm Hoài Thu ${ }^{1,3}$
}

\section{TÓM TẮT}

Liệu pháp huyết tương giàu tiểu câu tự thân (PRP) là một phương pháp mới điều trị bệnh lý đứt chóp xoay, trong đó có đứt bán phần gân trên gai. Mục tiêu: Đánh giá kết quả điều trị đứt bán phần gân trển gai bằng liệu pháp tiêm huyết tương giàu tiểu câuu tự thân dưới hướng dẫn siêu âm và khảo sát tác dụng không mong muốn của liệu pháp sau 12 tuần theo dõi. Đối tượng và phướng pháp nghiên cứu: Nghiên cứu can thiệp theo dõi dọc trong 12 tuần trên 40 bệnh nhânvới 42 gân đứt bán phần gân trên gai được tiêm PRP 3 mũi, çách nhau mỗi 3 tuân vào gân trên gai dưới hướng dẫn siêu âm. Kết quả: Sau 12 tuần điều trị,có sự cải thiện thang điểm VAS, góc dạng khớp vai và điểm SPADI: VAS và điểm SPADI trung bình giảm tương ứng từ $6,74 \pm 0,96$ điểm xuống $3,07 \pm 1,87$ điểm và từ $59,14 \pm 8,7$ điểm xuống 27,61 $\pm 16,1$ điểm, góc dạng khớp vai trung bình tăng từ $70,23 \pm 18,54$ độ lên 130,4 $\pm 38,2$ độ $(p<0,05)$. Tác dung không mong thường gặp là đau tăng tại vị trí tiểm trên 24 giờ là $57,1 \% \% ; 4,7 \%$ bệnh nhân có cảm giác nóng bừng mặt và không gặp các tác dụng không mong muốn nghiêm trọng. Kết luận: Liệu pháp tiêm PRP dưới hướng dẫn siêu âm có hiệu quả tốt trong điều trị đứt bán phần gân trên gai và là một liệu pháp an toàn.

Tứ khóa: Huyết tương giàu tiểu cầu tự thân, đứt bán phần gân trên gai, tiêm dưới hướng dẫn siêu âm.

\section{SUMMARY \\ ASSESSMENT OF THE EFFECTIVENESS OF ULTRASOUND- GUIDED INJECTION OF PRP IN THE TREATMENT OF PARTIAL SUPRASPINATUS TEAR}

Platelet-rich plasma therapy (PRP) is a new method for the treatment of partial rotator cuff tear, including partial supraspinatus tear. Aims: To assess the effectiveness of ultrasound-guided injection of PRP in the treatment of partial supraspinatus tear and evaluate adverse effects of this therapy after 12 weeks of follow-up. Methods: Controlled clinical trials were followed up to 12 weeks in 40 patients (42 tendons) partial supraspinatus tear received three,every 3 weeks, ultrasound-guided injections of PRP into the supraspinatus tendon. Results: After 12 weeks of treatment, there was an improvement in VAS,

${ }^{1}$ Trường Đại học Y Hà Nội

${ }^{2}$ Bệnh viên đa khoa tỉnh Hải Dương

${ }^{3}$ Bênh viên Đai hoc Y Hà Nôi

Chịu trách nhiệm chính: Nguyễn Thị Phương

Email: drphuonghd@gmail.com

Ngày nhận bài: 11.5 .2021

Ngày phản biên khoa hoc: 28.6.2021

Ngày duyệt bài: 12.7.2021 abduction angle of the shoulder joint, and SPADI scores in the research group: The average VAS and SPADI scores were decreased from $6,74 \pm 0,96$ to $3,07 \pm 1,87$ points and from $59,14 \pm 8,7$ to $27,61 \pm$ 16,1 points, the average abduction angle of the shoulder joint was increased from 70,23 $\pm 18,54$ degrees to $130,4 \pm 38,2$ degrees $(p<0,05)$. Side effects of the research group were $57,1 \%$ of the patients increased pain at the injection site over 24 hours, $4,7 \%$ feeling hot and there was no serious complication in the group. Conclusion: ultrasoundguided injection of PRP is good at the treatment of partial supraspinatus tear and this therapy is safe.

Key words: Autologous platelet-rich plasma, partial supraspinatus tear, ultrasound guided injection.

\section{I. ĐĂT VẤN ĐỀ}

Chóp xoay làmột cấu trúc giải phẫu gồm nhóm bốn gân bám vào đầu trên xương cánh tay đó là gân dưới vai, gân trên gai, gân dưới vai, gân tròn bé. Đứt bán phần gân trên gai là tổn thương thường gặp nhất của bệnh lý đứt chóp xoay3; thường gặp hơn ở những bệnh nhân trên 50 tuổi. Bệnh gây đau đớn, hạn chế vận động khớp vai, ảnh hưởng nhiêu đến các hoạt động của người bệnh.

Trên thế giới, từ 20 năm nay đã ứng dụng phương pháp huyết tương giàu tiểu cầu tự thân (platelet rich plasma - PRP) trong các lĩnh vực chấn thương thể thao (các loại viêm, đút gân). Với cơ chế chứa các yếu tố tằng trưởng và các cytokine chống viêm, PRP kích thích sự lành vết thương giúp phục hồi mô tổn thương một cách tự nhiên và sinh lý nhất. Đặc biệt trong khoảng 5-7 năm trở lại đây, trong điều trị đứt bán phần gân trên gai, PRP cho kết quả khả quan, ít tác dụng không mong muốn ${ }^{1,4-8}$. Tuy nhiên ở Việt Nam chúng tôi chưa thấy có nghiên cứu nào về vấn đề này. Vì vậy, chúng tôi tiến hành nghiên cứu đề tài: "Đánh giá kêt quả điều trị tôn thương đứt bán phần gân trên gai bằng liệu pháp huyêtt tương giàu tiểu cầu dưới hướng dấn của siêu âm" với 2 mục tiêu:

1. Nhận xét kết quả điểu trị tổn thương đứt bán phần gân trên gai bằng liệu pháp huyết tương giàu tiểu cầu dưới hướng dẫn của siêu âm.

2. Khảo sát tác dụng không mong muốn của liệu pháp sau 12 tuần theo dỗi.

II. Đốl TƯợNG VÀ PHƯƠNG PHÁP NGHIÊN CỨU 2.1. Đối tượng nghiên cứu. 
+ Gồm 40 bệnh nhân với 42 gân tổn thương đến khám tại Khoa Khám bệnh và Trung tâm Y khoa số 1 Tôn Thất Tùng, Bệnh viện Đại học Y Hà Nội từ tháng 1/2020 đến tháng 7/2021; được chẩn đoán đứt bán phần gân trên gai dựa và̀o các triệu chứng lâm sàng có đau khớp vai và hình ảnh chụp MRI khớp vai có đứt bán phần gân trên gai theo tiêu chuẩn Ellman (1990)đứt gân trên gai chia 3 độ: độ 1 tổn thương nhỏ $<3 \mathrm{~mm}$ hoặc $<1 / 4$ bề dày gân; đứt độ 2 tổn thương 3-6 mm hoặc <50\% bền dày gân; độ 3 tổn thương $>6 \mathrm{~mm}$ hoặc $>50 \%$ bề dầy gân 9 . Tất cả bệnh nhân chấp nhận tham gia nghiên cứu được điều trị bằng phương pháp tiêm PRP tự thân 3 mũi, mỗi mũi cách nhau 3 tuần, sử dụng bộ kit Tropocell, tiêm dưới hướng dẫn siêu ẩm. Quy trình điêu trị theo hướng dẫn của nhà sản xuất.

+ Tiêu chuẩn loaĩ trừ: Có tổn thương da tại vị trí tiêm, tiền sử phẫu thuật khớp vai, bệnh lý thần kinh ảnh hưởng đến vận động khớp vai, bệnh toàn thân nặng như: nhiễm trùng, suy giảm miễn dịch, bệnh tim mạch, bệnh lý ác tính, đang dùng chống đông. $\mathrm{Hb}<110 \mathrm{~g} / \mathrm{l}$, tiểu cầu $<$ $150.000 / \mathrm{mm}^{3}$, phụ nữ có thai...

\subsection{Phương pháp nghiên cứu}

Nghiên cứutiến cứu, can thiệp, theo dõi dọc đánh giá trước sau điều trị.

\section{Quy trinh nghiên cứu bao gồm:}

+ Đánh giá các đặc điểm điểm chung, đặc điểm lâm sàng của bệnh nhân đứt bán phần gẩn trên gai: tuổi, giới, thời gian bị bệnh, mức độ đau theo thang điểm VAS, đo góc dạng khớp vai, thang điểm SPADI.

+ Tất các các bệnh nhân được chụp cộng hưởng từ khớp vai đánh giá vị trí tổn thương gân trên gai, mức độ đứt gân trên gai và các tổn thương kèm theo.

+ Tiêm 2,5ml PRP tự thân phân tách bằng bộ kit Tropocell theo công nghê của hãng Estar Medical vào gân trên gai bị đứt dưới hướng dẫn siêu âm, tiêm 3 mũi, mỗi mũi cách nhau 3 tuần. Thủ thuật được tiến hành bởi bác sỹ chuyên khoa Cơ xương khớp. Sử dụng máy siêu âm Medison Accuvix v 10.0, đầu dò Linear tần số 513 Mhz tại phòng thủ thuật khoa Nội tổng hợp Bệnh viện Đại học Y Hà Nội.

+ Đánh giá kết quả điều trị dựa trên các thang điểm VAS, thang điểm SPADI và góc dạng của khớp vai tại các thời điểm trước điều trị (TO), sau điều trị 4 tuần (T4), sau điều trị 8 tuần (T8), và sau điều trị 12 tuần (T12). Tác dụng không mong muốn của liệu pháp được ghi nhận tại tất cả các thời điểm nghiên cứu.

2.3 Xử lý số liệu: Phần mềm SPSS 16.0

\section{KẾT QUẢ NGHIÊN CỨU}

3.1 Đắc điểm chung của bệnh nhân nghiên cứu. Tổng số 40 bệnh nhân nghiên cứu với 42 khớp vai được tiêm. Tuổi trung bình 56,52 \pm 11,7(29-82), độ tuổi 50- 70 tuổichiếm 52,4\%. Có $64,3 \%$ là nữ giới; tổn thương chủ yếu gặp ở vai phải $(64,3 \%)$. Thời gian bị bệnh trung bình $4,12 \pm 3,58$ tháng (1-12 tháng). $100 \%$ khớp vai khám tại thời điểm TO có mức độ đau vừa và nặng theo thang điểm VAS; SPADI trung bình59,14 \pm 8,7; góc dạng khớp vai bị hạn chế

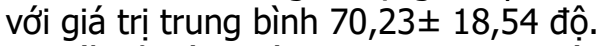

Tất cả các khớp vai được can thiệp đều được chụp cộng hưởng từ khớp vai: phân loại đứt bán phần gân trên gai theo Ellman (1990): Tổn thương đứt gân trên gai tại mặt khớp chiếm phần lớn 83,3\%; đứt gân trên gai độ $1(<3 \mathrm{~mm})$ chiếm $54,8 \%$; độ 2 (3-6mm) chiếm $40,5 \%$; độ 3 ( $>6 \mathrm{~mm}$ ) chiếm 4,7\%. Các tổn thương kèm theo: $21,4 \%$ có viêm gân nhị đầu; $26,2 \%$ khớp vaicó dịch bao hoạt dịch dưới cơ delta; $19,1 \%$ khớp vai có hẹp khoang mỏn cùng vai đòn, 4,8\% khớp vai có nốt canxi hóa gân trên gai.

3.2. Tác dụng không mong muốn của liệu pháp

Bảng 3.2.Tác dụng không mong muốn của liệu pháp( $n=42$ gân)

\begin{tabular}{|c|c|c|c|}
\hline \multirow{2}{*}{ Vị trí } & \multirow{2}{*}{$\begin{array}{c}\text { Tác dụng } \\
\text { khống mong } \\
\text { muốn }\end{array}$} & \multicolumn{2}{|c|}{$\begin{array}{c}\text { Nhóm can thiệp } \\
\text { (n=42 khớp vai) }\end{array}$} \\
\cline { 3 - 4 } & Số lượng & Tỷ lệ(\%) \\
\hline \multirow{2}{*}{ Tại chố } & Đau tăng 24h & 15 & $35,7 \%$ \\
\cline { 2 - 4 } & Nhiêm trùng & 0 & 0 \\
\hline \multirow{2}{*}{$\begin{array}{c}\text { Toàn } \\
\text { thân }\end{array}$} & Sốc & 0 & 0 \\
\cline { 2 - 4 } & $\begin{array}{c}\text { Nóng bứng, đau } \\
\text { đâuu chóng mặt }\end{array}$ & 2 & $4,7 \%$ \\
\hline Khác & Chảy máu & 0 & 0 \\
\hline
\end{tabular}

Nhận xét: Có 15 bệnh nhân đau tăng sau tiêm $(35,7 \%)$ ở mức độ nhe và 2 trường hợp có biểu hiện nóng bừng mặt sau tiêm $(4,7 \%)$.

3.3 Đánh giá kết quả điêuu trị đứt bán phân gân trên gai bằng liệu pháp huyết tương giàu tiểu câu tự thân dựa vào lâm sàng

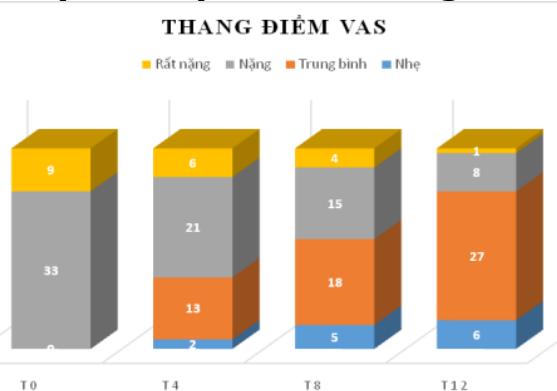

Biểu đồ 3.1 Mức độ đau trước và sau điều trị 12 tuần điều trị theo thang điểm VAS. 
Nhận xét: Mức độ đau theo VAS được cải thiện ngay từ tuần thứ 4 và giảm dần, duy trì hiệu quả sau 12 tuần theo dõi. Có 6 khớp vai $(14,6 \%)$ hoàn toàn hết đau $(p<0.05)$

Bảng 3.1 Đánh giá kêt quả điêu trị theo thang điểm VAS, SPADI, góc dạng khớp vaí

\begin{tabular}{|c|c|c|c|c|}
\hline & T0 & T4 & T8 & T12 \\
\hline VAS & $6,74 \pm 0,96$ & $5,21 \pm 1,04$ & $4,26 \pm 1,12$ & $3,07 \pm 1,87$ \\
\hline Góc dạng khớp vai & $70,23 \pm 18,54$ & $89,17 \pm 25,25$ & $109,1 \pm 31,5$ & $130,4 \pm 38,2$ \\
\hline SPADI & $59,1 \pm 8,73$ & $48,79 \pm 12,25$ & $36,79 \pm 12,25$ & $27,61 \pm 16,1$ \\
\hline \multicolumn{4}{|r}{$\mathbf{P}<\mathbf{0 , 0 5}$} \\
\end{tabular}

Nhận xét: Mức độ đau và chức năng vận động của khớp vai theo thang điếm VAS, SPADI, góc dạng khớp vaiđược cải thiện ngay từ tuần thứ 4 , mức độ cải thiện tăng dân và duy trì hiệu quá sau 12 tuần theo dõi $(p<0.05))$

\section{BÀN LUẬN}

4.1. Kết quả của liệu pháp tiêm PRP dưới hướng dẫn siêu âm trong điêuu trị đứt bán phân gân trên gai. Huyết tương giàu tiểu cầu (PRP) là một thể tích huyết tương tách chiết từ máu toàn phần có nồng độ tiểu cầu cao hơn mức cơ bản trong máu tĩnh mạch ban đầu. Trong PRP có chứa nhiều yếu tố tằng trưởng và một số các cytokine nên vừa có tác dụng chống viểm vữa có tác dung làm lành vết thương. Các yếu tố tăng trưởng như PDGF, VEGF, EGF, PDEGF, PDAF, ECGF tham gia vào quá trình làm lành vết thương thông qua kích thích hình thành mạch máu, phân chia tế bào, tăng sự biệt hóa tế bào làm lành các tổ chức. Các cytokine được tạo ra khi hoạt hóa tiểu cầu như Interleukin I receptor Antagonist (IL-IRA) là chất chống viêm mạnh làm giảm cường độ và thời gian của cơn đau, giải phóng beta endorphins có tác dụng giảm đau, chống viêm, các IL-4, IL-10 ngoài tác dụng chống viêm còn có vai trò tái tạo mô của gẩn, dây chằng ${ }^{1}$.

Nghiên cứu của chúng tôi chothấybắt đầu có sự cải thiện đáng kể điểm đau VAS ngay sau 4 tuần điều trị và kết quả giảm đau tiếp tục được duy trì tới tuần $12(p<0,05)$. Mức độ cải thiện điểm VAS giảm từ $6,74 \pm 0,96$ xuống hơn $50 \%$ còn $3,07 \pm 1,87$ sau 12 tuần điêu trị. Kết quả của chúng tôi tương tự nghiên cứu của Sengodan và cộng sự (2017) thực hiện trên 20 bệnh nhân có bệnh lý gân chóp xoay, điểm VAS tuần thứ 8 và tuần thứ 12 sau điêu trị PRP tự thân giảm từ 5,4 $\pm 0,9$ xuống còn $3,2 \pm 0,9$ và $2,6 \pm 0,8^{7}$. Năm 2013với tác giả Serdar nghiên cứu trên 40 bệnh nhân đứt gân trên gaicho thây có sự cải thiện đáng kể điểm VAS và kết quả được duy trì sau 1 năm thời điểm tiêm PRP $(p<0,001)^{4}$.

Sự cải thiện góc dạng khớp vai là một trong những tiêu chí chính đánh giá đáp ứng điều trị của tổn thương gân trên gai. Chúng tôi nhận thấy sau 4 tuần điều trị, bệnh nhân đã bắt đầu có cải thiện góc dạng khớp vai, mức độ cải thiện góc dạng khớp vai tăng dần đến tuần thứ 12 $(p<0,05)$. Góc dạng của khớp vai trung bình sau 12 tuần điều trị tăng từ $70,23 \pm 18,54$ độ lên $130,4 \pm 38,2$ độ, có ý nghĩa thống kê $(p<0,05)$. Kết quả này tương tự kết quả của Serdar và cộng sự (2013); sau 4 tuần, 8 tuần và 12 tuần điêu trị PRP tự thân, góc dạng khớp vai tăng từ 90 độ lên lần lượt 110,140 và 160 độ $(p<0,05)^{4}$.

Đánh giá chức năng vận động khớp vai qua thang điểm SPADI. Nghiển cứu của chúng tôi cho thây sau 12 tuần điều trị điểm SPADI giảm từ $59,1 \pm 8,73$ xuống còn $27,61 \pm 16,1$. Kết quả này tương tự kết quả của Serdar và cộng sự (2013) điểm SPADI ở nhóm sử dụng PRP tự thân sau 12 tuần điêu trị giảm từ 77,5 xuống 27,6 điểm $(p<0,05)^{4}$. Theo Dong-wook và cộng sự (2013) nghiên cứu trên 35 bệnh nhân có tổn thương gân trên gai hoặc đứt bán phần dưới $1 \mathrm{~cm}$ : điều trị với PRP cho thấy điểm SPADI sau 12 tuần giảm từ 62,3 xuống còn 21,1 điểm; hiệu quả hơn so với dùng phương pháp châm cứu $(p<0,05)^{6}$.

Nghiên cứu theo dõi sau 12 tuần của chúng tôi cho thấy liệu pháp tiêm PRP điều trị đứt bán phần gân trên gai có hiệu quả giảm đau, cải thiện chức năng và tầm vận động của khớp vai được đánh giá thông qua thang điểm VAS, SPADI, góc dạng khớp vai.

\subsection{Tác dụng không mong muốn của}

liệu pháp. Trong nhóm can thiệp có 42 khớp vai tiểm PRP tự thân có 24 khớp vai đau tăng sau tiêm $(57,1 \%)$, tuy nhiên mức độ đau chỉ ở mức độ nhẹ, trong đó có 10 trường hợp không cần dùng thuốc giảm đau và 14 trường hợp bệnh nhân phải dùng thuốc giảm đau paracetamol $0,5 \mathrm{~g} \times 2$ viên/ ngày $\times 2$ ngày. Có 2 bệnh nhân $(4,7 \%)$ nóng bừng mặt sau tiêm; một bệnh nhân huyết áp tối đa sau tiêm tăng $10 \mathrm{mmHg}$ và một bệnh nhân tăng huyết áp tối đa sau tiêm 15 $m m H g$. Đây là bệnh nhân có tiền sử tăng huyết áp trước đó và triệu chứng hết nhanh sau 30 phút nghỉ ngơi. Ngoài ra, không có biến chứng nghiêm trọng nào xảy ra trong thời gian tiến hành thủ thuật và sau 12 tuần được chúng tôi 
theo dõi. Trong nghiên cứu Nguyễn Trần Trung ${ }^{8}$ khi điều trị viêm lồi cầu ngoài xương cánh tay bằng PRP tự thân có $54,8 \%$ BN đau tăng tại vị trí tiêm, trong đó $38,7 \%$ bệnh nhân hết đau sau 3 ngày và $16,1 \% \mathrm{BN}$ hết đau sau 1 tuần. Nghiên cứu của Segodan và cộng sự (2017) cũng cho thấy tác dụng không mong muốn gặp nhiều nhất sau tiêm PRP tự thân là đau, tuy nhiên thường nhẹ và tự khỏi ${ }^{7}$. Các nghiên cứu trên thế giới và Việt Nam cho thấy rằng liệu pháp huyết tương giàu tiểu cầu tự thân là một phương pháp điều trị an toàn, ít biến chứng.

\section{KẾT LUẬN}

Tiêm huyết tương giàu tiểu cầu tự thân dưới hướng dẫn siêu âm điều trị đứt bán phần gân trên gai bước đầu cho thây có hiệu quả lâm sàng trong giảm đau, cải thiện chức năng và tầm vận động khớp vai.TiêmPRP tự thân là liệu pháp an hiệu quảvà an toàn.

\section{TÀI LIÊU THAM KHẢO}

1. Bùi Hải Bình (2016). Nghiên cứu điều trị bệnh thoái hóa khớp gối nguyên phát bằng liệu pháp huyết tương giàu tiểu cầu tự thân. Luận Án Tiến Sĩ Y Học, Đại Học Y Hà Nội.

2. Eustace JA, Brophy DP, Gibney RP, et al (1997). Comparison of the accuracy of steroid placement with clinical outcome in patients with shoulder symptoms. Ann Rheum Dis, 1997. 56(1): p. 59-63. DOI: 10.1136/ard.56.1.59.

3. Goutallier D (1997). Pathologie de la Coiffe des Rotateurs. Traité d'Appareil locomoteur, 14-350-A-10.

4. Kesikburun S, Tan AK, Yilmaz B, et al (2013).Platelet-rich plasma injections in the treatment of chronic rotator cuff tendinopathy: a randomized controlled trial with 1-year follow-up. Am J Sports Med, 2013. 41(11): p. 2609-16. DOI: 10.1177/0363546513496542.

5. Randelli PS, Arrigoni $P$, Cabitza $P$, et al (2008). Autologous platelet rich plasma for arthroscopic rotator cuff repair. A pilot study. Disabil Rehabil. 30(20-22): p. 1584-9. DOI: 10.1080/09638280801906081

6. Rha DW, Park GY, Kim YK, et al (2013). Comparison of the therapeutic effects of ultrasound-guided platelet-rich plasma injection and dry needling in rotator cuff disease: a randomized controlled trial. Clin Rehabil. 27(2): p. 113-22.DOI: $10.1177 / 0269215512448388$.

7. Sengodan VC, Kurian S, and Ramasamy $R$ (2017). Treatment of Partial Rotator Cuff Tear with Ultrasound-guided Platelet-rich Plasma. J Clin Imaging Sci, 2017. 7: p. 32.DOI: 10.4103/ jcis.JCIS_26_17.

8. Nguyến Trân Trung (2016). Đánh giá kết quả liệu pháp huyết tương giàu tiểu câu ở bệnh nhân viêm điểm bám lồi cầu ngoài xương cánh tay. Đại Học Y Hà Nôi, Hà Nội.

9. Patte, D.,(1990). Classification of rotator cuff lesions. Clin Orthop Relat Res, (254): p. 81-6.

\section{KẾT QUẢ ĐIỀU TRI VIÊM PHỔI NẶNG Ở TRẺ TỪ 1 THÁNG ĐẾN 5 TUỔI TẠI TỈNH QUẢNG NINH}

\section{TÓM TẮT}

Nghiên cứu tiến cứu mô tả cắt ngang trên 81 trẻ từ 1 tháng đến 5 tuổi được chẩn đoán viêm phổi nặng điều trị tại bệnh viện Đa khoa tỉnh Quảng Ninh và bệnh viện Sản Nhi Quảng Ninh từ 7/2020 đến 6/2021. Viêm phổi nặng gặp chủ yếu ở trẻ dưới 12 tháng tuổi (chiếm $77,7 \%$ ). Bệnh nhân vào viên chủ yếu ở mức độ suy hô hấp độ II (chiếm 74,1\%), có $25,9 \%$ bệnh nhân suy hô hấp độ I. $97,5 \%$ bệnh nhân có kết quả điều trị khỏi bệnh. Thoời gian sốt trung bình của nhóm nghiên cứu là: $2 \pm 1,25$ ngày. Thời gian sử dụng kháng sinh tĩnh mạch trung bình là 7,9 $\pm 2,17$ ngày. Thời gian thở oxy và thời gian điều trị trung bình lần lượt là: $2,6 \pm 1,69$ ngày và $8,2 \pm 2,31$ ngày. Có mối liên quan giữa $\mathrm{SpO}_{2}$ lúc vào viện và số ngày thở oxy.

\footnotetext{
${ }^{1}$ Bệnh viện đa khoa tỉnh Quảng Ninh, ${ }^{2}$ Bệnh Viện Nhi Trung Uơng, Chịu trách nhiệm chính: Trần Nhị Hà Email: nhiha72@gmail.com Ngày nhận bài: 12.5 .2021 Ngày phản biện khoa học: 29.6.2021 Ngày duyệt bài: 13.7.2021
}

\section{Trần Nhị Hà ${ }^{1}$ Lê Thị Hồng Hanh ${ }^{2}$}

Có mối liên quan giữa tiền sử đẻ non và thời gian điều trị trung bình $(p<0,05)$.

Tư khóa: viêm phổi nặng, điều trị, kết quả, trẻ em

\section{SUMMARY}

\section{RESULT OF TREATMENT OF SEVERE PNEUMONIA IN CHILDREN FROM 1 MONTH TO FIVE YEARS OLD IN QUANG NINH PROVINCE}

We conducted a prospective, cross-sectional descriptive study on 81 children (aged 1 month to 5 years) with severe pneumonia hospitalized from July 2020 to June 2021 at Quang Ninh General Hospital and Quang Ninh Obstetrics and Pediatrics Hospital. Severe pneumonia was observed mainly in children under 12 months $(77.7 \%)$. $75.3 \%$ of patients admitted to the hospital with grade II respiratory failure and $24.7 \%$ patients with grade I. $97.5 \%$ of patients were discharged with good results. The mean duration of fever was $2 \pm 1.25$ days. The duration of oxygen therapy was $2.6 \pm 1.69$ days. The mean duration of parenteral antibiotic therapy was $7.9 \pm$ 2.17 days. The average length of hospital stay was 8.2 \pm 2.31 days. There were correlations between $\mathrm{SpO}_{2}$ on admission and duration of oxygen therapy, history 